\title{
A systematic review of interventions to improve knowledge and self-management skills concerning contraception, pregnancy and breastfeeding in people with rheumatoid arthritis
}

Dr llana N Ackerman

The University of Melbourne and Melbourne Health, Melbourne, Australia

Dr Gene-Siew Ngian

The University of Melbourne and Melbourne Health, Melbourne, Australia

Associate Professor Sharon Van Doornum

The University of Melbourne and Melbourne Health, Melbourne, Australia

Associate Professor Andrew M Briggs

Arthritis and Osteoporosis Victoria, Melbourne, Australia and Curtin University, Perth, Australia

Corresponding author

Dr llana Ackerman

Melbourne EpiCentre

7East, Main Block, Royal Melbourne Hospital, Parkville, Victoria 3050, Australia

Phone: $+61393422153 \quad$ Fax: +61393428780

Email: i.ackerman@unimelb.edu.au 


\section{Abstract}

This systematic review aimed to determine the effectiveness of interventions for improving knowledge and/or self-management skills concerning contraception, pregnancy and breastfeeding in people with rheumatoid arthritis (RA). We searched 4 databases (Medline, CINAHL, Cochrane Trials, Psyclnfo) using a comprehensive search strategy. Studies were eligible if they were prospective, published in English from 2004-2015, included participants with RA, and tested an intervention designed to improve knowledge and/or self-management skills relating to family planning, pregnancy or breastfeeding. As no studies met the latter criterion, the search strategy was expanded to include all prospective studies evaluating RA educational and/or selfmanagement interventions. Data on study characteristics, participant characteristics and program content were extracted to summarise the evidence base for interventions to support people with RA during their reproductive years. Expanded literature searches identified 2290 papers, of which 68 were eligible. Of these, 9 papers (13\%) specifically excluded pregnant women/breastfeeding mothers or recruited only older people. Only 1 study (1\%) explicitly evaluated pregnancy-focused education via a motherhood decision aid, while 8 studies (12\%) incorporated relevant (albeit minor) components within broader RA educational or self-management interventions. Of these, 3 studies provided methotrexate education in relation to conception/pregnancy/breastfeeding; 3 incorporated discussions on RA and relationships, impact of RA on the family, or sexual advice; 1 provided information regarding contraception and fertility; and 1 issued a warning regarding use of biologic therapy in pregnancy/breastfeeding. In conclusion, information regarding family planning, pregnancy or breastfeeding represents a negligible part of published RA educational interventions, with scope to develop targeted resources.

\section{Word count: 250}

\section{Keywords}

Patient education; rheumatoid arthritis; family planning, contraception, pregnancy, breastfeeding 


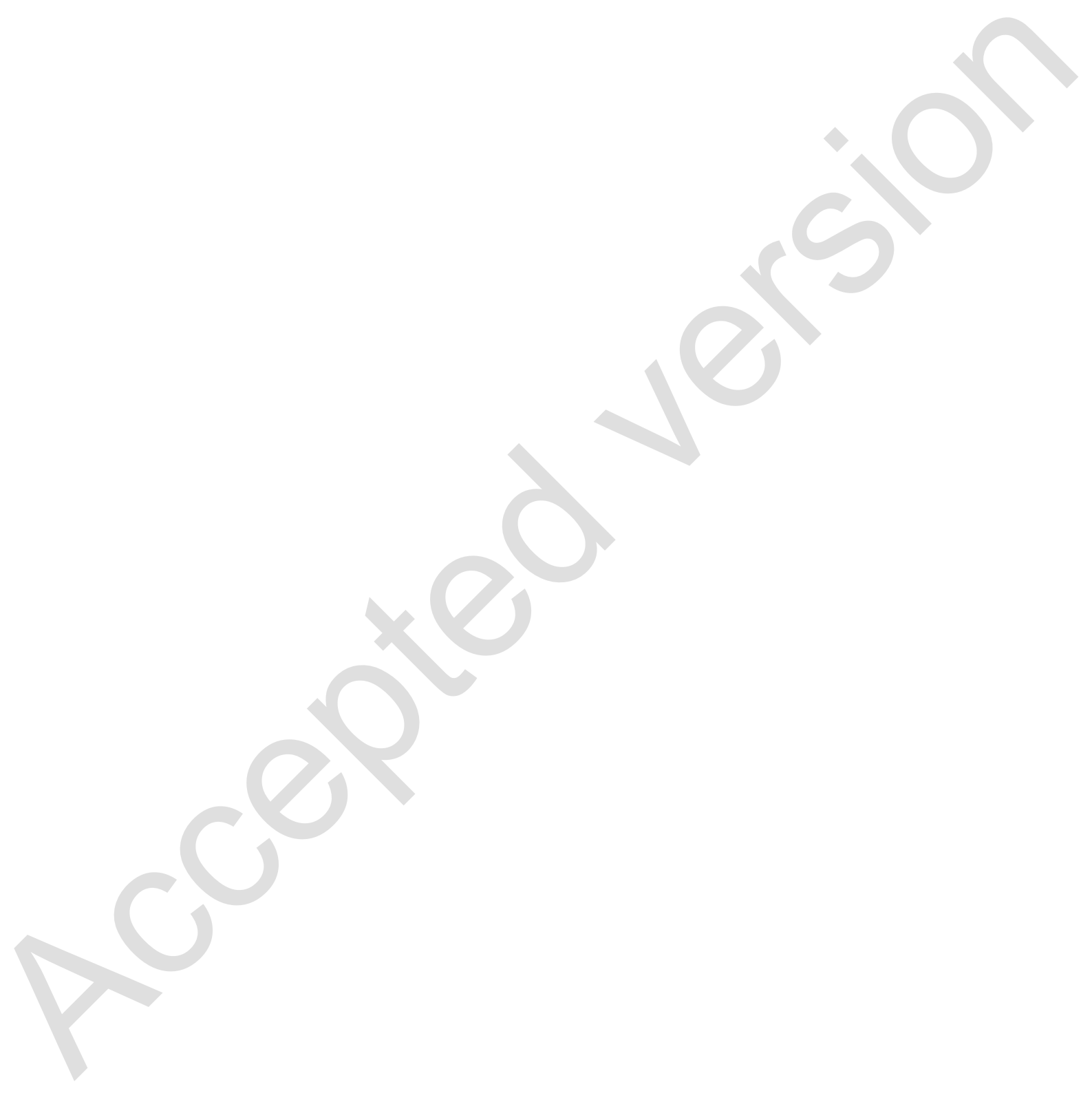




\section{Introduction}

Rheumatoid arthritis (RA) substantially impacts women of reproductive age [1], and the symptoms and physical limitations associated with the disease, as well as the potential side-effects of disease-modifying medications, represent important considerations in family planning and disease management in early parenting [2-4]. Pregnancy raises a plethora of complex issues for women with RA and their families to consider, particularly around the cessation of medications, the management of disease flares, and the effects of drug exposure on an unborn baby or breastfed child [5]. Disease management approaches will usually need to be modified over the course of pregnancy and breastfeeding and as some disease-modifying anti-rheumatic drugs (DMARDs) are teratogenic (such as methotrexate), education regarding effective contraception and avoidance of unplanned pregnancy is also critical for people with RA during their reproductive years $[4,6]$. Our recent qualitative research found that the lack of accessible and specific information concerning the safety and toxicity of RA medications was the most important issue reported by women who were pregnant, planning a pregnancy, or who had been pregnant in the last five years [7]. Receiving inconsistent advice from health professionals concerning pharmacological management of their RA was a major source of frustration and confusion for many women, and a desire for enhanced peer support and practical education to support women in caring for their young baby was also emphasised. There is, then, a clear need for appropriate education and support for women with RA (and their families) who are contemplating pregnancy, currently pregnant or breastfeeding to provide a more informed and acceptable patient journey.

Patient education is considered an integral part of routine care for people with inflammatory arthritis [8] and this can be complemented by self-management training to enhance knowledge and skills and empower people to better manage their health across the disease continuum. Although many diverse models exist, perhaps the most well-known programs internationally are the Stanford Arthritis Self-Management Program and the Chronic Disease Self-Management Program developed by Lorig and colleagues [9]. Self-management interventions commonly cover a range of disease-relevant skills including problem-solving, informed decision-making, and relationships 
with health professionals, while aiming to influence health attitudes, beliefs and behaviours [10]. To date, systematic reviews of patient education and self-management interventions in RA (including one Cochrane review) have all been broad in scope and have not focused on the specific needs of women who are pregnant or considering pregnancy [8,10-13], despite emerging evidence that this group of patients have specific educational needs [7,14]. The content and outcomes of educational interventions for this patient group therefore remain unknown. This systematic review aimed to evaluate the effectiveness of interventions designed to improve knowledge and/or self-management skills concerning contraception, pregnancy and breastfeeding in people with RA. 


\section{Methods}

\section{Study design}

A systematic review was undertaken and documented according to the Preferred Reporting Items for Systematic Reviews and Meta-Analyses (PRISMA) checklist [15].

\section{Search strategy}

Four key electronic databases were searched from January 2004 to March 2015 to identify potentially relevant studies (Cochrane Controlled Trials Register, Cumulative Index to Nursing and Allied Health Literature (CINAHL), MEDLINE and Psyclnfo). A standardised search strategy was based on that used for an earlier Cochrane review of patient education for adults with RA [11], with the addition of specific search terms relating to pregnancy, breastfeeding/lactation/nursing, conception, contraception and family planning:

(rheumatoid arthritis OR arthritis) AND (clinical trial OR study OR evaluation OR program OR experiment) AND (health promotion OR patient education OR behavior therapy OR behaviour therapy OR occupational therapy OR self care OR psychological adaptation OR counseling OR counselling) AND (pregnan* OR lactat* OR breast* OR nursing mother OR conception OR contracept* OR family planning) NOT review

Although search terms were kept consistent, the search format was adapted for each database, as appropriate.

\section{Inclusion criteria}

To be eligible for inclusion in the review, studies were required to have: used a prospective design (not limited to randomised controlled trials), been published in English since 2004, included participants with RA, and tested an intervention designed to improve knowledge and/or selfmanagement skills relating to family planning, pregnancy or breastfeeding. Studies published prior 
to 2004 were excluded to optimise relevance of the findings given significant changes in the pharmacological management of RA over the past decade [16] and the potential impact of these changes on the content of disease-related education.

\section{Selection of studies and revision of search strategy}

All titles and abstracts identified from the database searches were screened independently by 2 reviewers. As no studies were identified that met the intervention criterion, the search strategy was revised and a broader search was conducted across the same 4 electronic databases to identify all prospective studies evaluating educational and/or self-management interventions for people with RA that were published in English from January 2004 to March 2015. The following search strategy was used:

(rheumatoid arthritis OR arthritis) AND (clinical trial OR study OR evaluation OR program OR experiment) AND (health promotion OR patient education OR behavior therapy OR behaviour therapy OR occupational therapy OR self care OR psychological adaptation OR counseling OR counselling) NOT review

Titles and abstracts retrieved from the second literature search were also screened independently by 2 reviewers according to the revised inclusion criteria, and the full texts of eligible papers were obtained. Where eligibility was unclear from title and abstract screening, the full text was obtained. Two reviewers independently reviewed the full text papers to confirm eligibility, with any discordance resolved through discussion (with referral to a third independent reviewer, where required). Where two or more papers derived from the same study clearly met the inclusion criteria (for example, follow-up studies reporting longer-term outcomes or additional interventions) each paper was included in the review but their relationship was noted (Online Resource 1). The reference lists of all included papers were also screened to identify any additional papers that met the inclusion criteria for the review. The ClinicalTrials.gov (https://clinicaltrials.gov) and Australian 
New Zealand Clinical Trials Registry websites (www.anzctr.org.au) were also searched to identify registered trials of relevance, and related publications (where available) were obtained.

\section{Data extraction}

The following data were independently extracted by 2 reviewers from all included studies:

- relevant participant exclusion criteria (pregnancy or breastfeeding status, age restrictions);

- participant characteristics (sample size, proportion of female participants, age of participants, proportion of sample with a diagnosis of RA); and

- whether the intervention(s) included an educational and/or self-management component relating to contraception, conception, pregnancy and/ or breastfeeding.

Any disagreements were resolved through discussion in order to reach consensus, and a third independent reviewer was enlisted where required. Information about the use of outcome measures relevant to conception/pregnancy/breastfeeding knowledge was also extracted from studies where interventions included a pregnancy-related component. Outcomes data were not extracted from included studies because for most studies the effect of individual program components could not be determined (for example, the effect of specific education related to pregnancy). Where information provided in a published paper was unclear, clarification was sought from the corresponding author by email. 


\section{Results}

\section{Study selection}

Figure 1 provides an overview of the study screening and selection process. In total, 2290 potentially eligible papers were identified from the revised database searches. After excluding 143 duplicate papers and 2073 papers that did not meet the eligibility criteria, 74 full text papers were retrieved to confirm their eligibility. Of these, a further 11 papers were excluded, including 2 papers where it was not clear that people with RA were included in the study sample (1 study included people with any type of arthritis or persistent joint pain but the proportion of participants with RA was not reported; 1 study included people with rheumatic diseases but the proportion of participants with RA was not reported). Screening of reference lists and searches of clinical trial registries identified 5 additional eligible papers, resulting in a total of 68 papers included in the review.

\section{Characteristics of included studies}

As shown in Table 1, the majority of included studies were randomised controlled trials $(n=45$, $66 \%$ ). Non-randomised prospective designs (including single group pretest-posttest designs) were also common ( $n=19,28 \%$ ) while only 1 study used a mixed-methods design. Most studies were conducted in Europe $(n=30,44 \%)$, followed by North America $(n=28,41 \%)$. The included studies were undertaken in a range of healthcare and community settings including hospitals or clinics, community health or rehabilitation centres and the general community. Table 1 summarises the age, gender and diagnosis characteristics of all participants in the included studies. Forty-five studies (66\%) recruited people with RA only (or people with RA and their partners), while the remaining 23 studies included a broader range of diagnoses including $\mathrm{RA}$. A detailed summary of each of the 68 included studies (including information about interventions and controls) is provided in Online Resource 1. 


\section{Studies with exclusion criteria related to pregnancy, breastfeeding or age}

Of the included papers, 3 specifically excluded pregnant women or breastfeeding mothers [17-19] and one recruited only participants who were rheumatologist-confirmed candidates for methotrexate therapy [20]. As methotrexate is contraindicated during pregnancy and the preconception period [21], it is unlikely that women who were pregnant or considering pregnancy were included in this study sample. As shown in Table 2, 5 papers reported studies that recruited only older age groups (people aged 50 years and over [22-24], people aged 55 years and over [25], or people aged 65 years and over [26]), thereby likely excluding women of reproductive age. A further 10 studies did not report detailed eligibility criteria [27-36].

\section{Studies that included relevant intervention components}

Of the 68 included papers, only 1 (1\%) explicitly evaluated pregnancy-focused education (Table 3 ). Eight studies (12\%) described interventions containing a minor component that could be considered relevant to conception, contraception, pregnancy or breastfeeding, within broader RA educational or self-management interventions. The relevant content of these interventions is described below.

\section{Pregnancy-focused education}

Meade et al [37] recently published the results of their RCT describing the development and evaluation of a 'motherhood choices decision aid' for RA. The Australian decision aid tool was designed to assist women with RA in making informed choices about having children, or having more children. Health professionals and women with RA and their partners were involved in the development of this resource which includes information on RA, pregnancy and medications, decision-making activities, and links to available resources [38].

\section{Information regarding medication safety}

In their study, Fraenkel et al [39] tested a web-based decision support tool designed to inform people with RA about biologic DMARD therapy. This support tool included a warning regarding the 
current lack of information about the effect of biologic medications on an unborn child and advised participants to inform their doctor prior to commencing therapy if they were pregnant, planning a pregnancy, or breastfeeding. Li et al [20] evaluated a web-based methotrexate decision aid for people with RA that incorporated a value clarification module and an information module. The value clarification module asked participants to rate the perceived importance of a set of statements; this information was then provided to the rheumatologist to facilitate discussion regarding methotrexate use. As part of this module, participants were asked to rate the importance of becoming pregnant (or their partner becoming pregnant) over the next 12 months. The accompanying education module covered 6 key topics including planning a family and methotrexate use. Ciciriello et al [40] designed a multimedia patient education program that aimed to improve patient knowledge about methotrexate treatment for RA. This program included content regarding contraindications to taking methotrexate, situations where methotrexate should be ceased, and precautions relating to the use of methotrexate in the context of conception and breastfeeding.

\section{Information about fertility and contraception}

Although Homer et al [19] excluded women who were pregnant or breastfeeding from their study of DMARD education, the authors reported that they sought permission from participants for group discussions about fertility and contraception. Participants in this study were also offered the option of discussing these issues privately after the education session, or via a nurse helpline. In their study, Mohammad et al [33] administered a methotrexate patient information booklet. While the content of the information booklet was not specified, the authors indicated that contraception use and the side effect profile of methotrexate were outlined in the booklet.

\section{Information about relationships and sexual advice}

In a study of occupational therapy for people with early RA, Hammond et al [41] offered optional intervention program components that included sexual advice, and discussion about the effect of RA on relationships. In a later unrelated study, Hammond and colleagues [42] evaluated a modular behavioural arthritis education program that included a facilitated discussion about the 
impact of arthritis on the family. Finally, the study by Ellard et al [34] evaluated the effect of targeted education for people with RA and their partners, provided in the form of day-long workshops. One of the workshops involved small-group discussions on relationships, led by a specialist registrar and a psychologist.

\section{Studies that utilised relevant outcome measures}

Of the 9 studies that incorporated a pregnancy-related intervention component, 5 utilised a relevant outcome measure to assess patient knowledge or satisfaction. Ciciriello and colleagues [40] developed the Methotrexate in Rheumatoid Arthritis Knowledge test (MiRAK) and used this to evaluate changes in knowledge after viewing of their methotrexate multimedia patient education program. This instrument contains 4 items that assess patient understanding of whether it is safe to take methotrexate during pregnancy and breastfeeding, whether it is safe to become pregnant 3 weeks after methotrexate therapy has been ceased, and contraceptive use for men and women taking methotrexate. The MiRAK instrument was also used to evaluate patient knowledge in the methotrexate decision aid study by Li et al [20]. Homer et al [19] used the Satisfaction with Information about Medicines Scale (SIMS) [43] in their study. The SIMS contains items relating to whether adequate information was given about unwanted effects of medication, the risks of side effects, and the impact of medications on an individual's sex life. Meade et al [37] described the development of a new Pregnancy in Rheumatoid Arthritis Questionnaire (PiRAQ) designed to assess knowledge outcomes in their RCT. The PiRAQ contains 39 items that cover knowledge around RA and its impacts, the effects of RA medicines during conception, pregnancy and breastfeeding, and post-natal aspects. The study by Mohammad et al [33] used a questionnaire that assessed awareness of the reason for taking folic acid and awareness of contraception use following administration of their methotrexate information booklet. 


\section{Discussion}

This is the first systematic review of interventions designed to improve knowledge and/or selfmanagement skills concerning contraception, pregnancy and breastfeeding in people with RA. We only identified one study [37] that specifically evaluated pregnancy-focused education or selfmanagement support for people with RA, revealing a critical gap in the published literature. Additionally, most studies (88\%) evaluating broader RA education or self-management programs did not include any interventional component relating specifically to family planning, pregnancy or breastfeeding. There is, therefore, considerable scope to develop targeted resources or programs to effectively support women with RA and their families in negotiating the potentially complex journey to parenthood.

Our review also identified that most of the research evaluating education or self-management interventions for people with RA has involved older individuals, with average ages for the included studies ranging up to 79 years (Online Resource 1). Although women constituted the majority of participants in all of these studies, it is clear that these study samples are not representative of younger women with RA who are likely to be making decisions about contraception and pregnancy. Importantly, several studies excluded people aged 50 years or less, while others explicitly excluded women who were pregnant or breastfeeding. Consequently, the outcomes of these broader RA programs are unlikely to be generalisable to women who are currently pregnant or planning pregnancy. Notably, our earlier qualitative research highlighted that the specific information needs of younger women (such as managing a pregnancy with RA) were not being appropriately addressed [7] and this is supported by the results of this systematic review. This finding is of particular relevance given key recommendations from a recent European League Against Rheumatism (EULAR) taskforce report that patient education for people with inflammatory arthritis should be needs-based and tailored to individual life circumstances [8], and our previous research demonstrating the strong preference of younger women with RA not to be grouped with older individuals with regard to disease-related educational resources [7]. 
The recent study by Meade et al [37] involved women with RA who were contemplating having children (or more children). This research found that participants who were given a motherhood decision aid resource had a greater increase in knowledge around RA and pregnancy-related topics and a greater reduction in decisional conflict, compared to a no intervention control group. However, follow-up of participants beyond the immediate post-intervention period was not undertaken and both the relatively high dropout rate (23\%) and absence of an intention-to-treat analysis should be considered when interpreting the study results. Despite some limitations in the quality of evidence provided by this study, it suggests that a decision aid could present a valuable resource for women with RA and their families, consistent with Cochrane review evidence demonstrating that decision aids can reduce decisional conflict in people facing health treatment or screening decisions [44]. An evaluation of the motherhood decision aid's effectiveness in clinical practice is now warranted.

Where relevant intervention components were identified in the other included studies, many of these were limited to medication safety (particularly around methotrexate use) rather than adopting a broader self-management paradigm to address disease-related problem solving skills, resource utilisation and patient-health professional relationships [10] in relation to reproductive and postnatal issues. While medication safety has been identified by women with RA as a key educational priority for them [7], this narrow focus does not address other important aspects of effective chronic disease management. Research from our group and others has shown that women with RA can struggle profoundly during the post-natal period $[14,45]$ and that they seek practical strategies and emotional support to enable them to cope with caring for a young baby [7]. Although some interventions included discussions regarding the impact of arthritis on the family and relationships, it is clear that information and support spanning the entire pre-pregnancy/pregnancy/post-natal continuum is needed. This could be provided via multidisciplinary approaches incorporating primary care, rheumatology and obstetrics input. Peer support from women with RA who have already experienced pregnancy could also form an important part of a targeted educational program. Future research evaluating new interventions should consider carefully how best to assess study outcomes, given the scarcity of tools for assessing skills and knowledge regarding 
the management of RA in the context of family planning and pregnancy. Aside from medicationfocused tools (such as the MiRAK), the Educational Needs Assessment Tool (ENAT) could be used to assess potential educational needs including how arthritis might affect one's children, the ways arthritis is affecting an individual, and the side-effects of medications [46]. The new PiRAQ tool could be valuable for evaluating pregnancy-related knowledge outcomes, although further psychometric evaluation is likely needed [37].

The findings of our systematic review have several implications for practice. A recent paper reporting the proceedings of a multi-disciplinary American College of Rheumatology Reproductive Health Summit highlighted the importance of pregnancy planning and pre- and post-natal counselling for women with autoimmune and systemic inflammatory conditions [47]. However, given the paucity of educational interventions with demonstrated effectiveness, the onus is on treating clinicians (for example, primary care physicians, rheumatologists, obstetricians and/or pharmacists) to provide relevant information to women who are pregnant or planning a pregnancy. While provision of information remains a key component of clinical care (including team-based care) [48] and several online medication resources are available [47], these may not be sufficient for reinforcing key messages. For example, a recent clinical audit of sexually active women with rheumatologic conditions including RA found that only $57 \%$ of women on known teratogenic DMARDs were using effective contraception despite receiving specialist rheumatology care at a large teaching hospital [49]. A hospital-based study in Turkey also highlighted suboptimal contraceptive use among female patients with RA [50]. Appropriate education and support should also be made available outside the clinical setting as information seeking may not coincide with the timing of clinical consultations. Additionally, decisions regarding pregnancy in the context of RA can require considerable contemplation over time, and women may want to involve their partners and others who may not be able to attend clinic appointments. Educational programs and resources that can be accessed outside the clinical setting (such as the motherhood choices decision tool [38]) would also be of considerable value to clinicians as there is often inadequate time to cover all the educational aspects of RA medications within consultations. There is also a need to develop educational resources that are accessible to women with RA who live in rural and 
remote areas, and those who may be unable to travel (for example due to illness, functional limitations or advanced pregnancy). As suggested by Kavanaugh and colleagues [47], there is also potential for consumer organisations to partner and co-develop 'risk communication tools' regarding pregnancy and chronic conditions.

We acknowledge several limitations to our research. We searched the published, peer-reviewed literature and it is possible that reports of other interventions may exist in the grey literature, or that other effective, unpublished programs may be available in clinical or community settings. We also acknowledge that our determination of relevant intervention components was based on information provided in the published papers. Several of the included studies stated that they provided education regarding medication use or side effects as part of their intervention program and this may have feasibly included information relating to pregnancy or breastfeeding, although it was not explicitly mentioned. Finally, we did not grade levels of evidence or apply a risk of bias filter to the included studies since outcomes data were not extracted.

In conclusion, the current evidence base of effective, published interventions to inform and support women with RA and their families during their reproductive years is extremely limited and the quality of evidence for specific interventions is modest. There is significant scope to develop and evaluate new programs designed to improve knowledge and self-management skills in this area. Future models of education and support should encompass more than just the medication safety aspect of RA education and span the entire pre-pregnancy/pregnancy/post-natal continuum in order to be of most value to women with RA and their families.

\section{Word count}

3718 words 


\section{References}

1. Ostensen M, Forger F (2009) Management of RA medications in pregnant patients. Nat Rev Rheumatol 5(7):382-90.

2. Chambers CD, Tutuncu ZN, Johnson D, Jones KL (2006) Human pregnancy safety for agents used to treat rheumatoid arthritis: Adequacy of available information and strategies for developing post-marketing data. Arthritis Res Ther 8(4):215.

3. Signore C, Spong CY, Krotoski D, Shinowara NL, Blackwell SC (2011) Pregnancy in women with physical disabilities. Obstet Gynecol 117(4):935-47.

4. Soh MC, Nelson-Piercy C (2015) High-risk pregnancy and the rheumatologist. Rheumatology 54(4):572-87.

5. Cush JJ, Kavanaugh A (2014) Editorial: pregnancy and rheumatoid arthritis - do not let the perfect become the enemy of the good. Curr Opin Rheumatol 26(3):299-301.

6. Ngian G-S, Briggs AB, Ackerman IN, Van Doornum S (in press) Management of pregnancy in women with rheumatoid arthritis. Med J Aust.

7. Ackerman IN, Jordan JE, Van Doornum S, Ricardo M, Briggs AM (2015) Understanding the information needs of women with rheumatoid arthritis concerning pregnancy, post-natal care and early parenting: A mixed-methods study. BMC Musculoskelet Disord 16:194.

8. Zangi HA, Ndosi M, Adams J, Andersen L, Bode C, Boström C, van Eijk-Hustings Y, Gossec L, Korandová J, Mendes G, Niedermann K, Primdahl J, Stoffer M, Voshaar M, van Tubergen A (2015) EULAR recommendations for patient education for people with inflammatory arthritis. Ann Rheum Dis 74(6):954-62.

9. Lorig KR, Holman HR (2003) Self-management education: History, definition, outcomes and mechanisms. Ann Behav Med 26(1):1-7.

10. Iversen MD, Hammond A, Betteridge N (2010) Self-management of rheumatic diseases: State of the art and future perspectives. Ann Rheum Dis 69(6):955-63.

11. Riemsma RP, Kirwan JR, Taal E, Rasker JJ (2003) Patient education for adults with rheumatoid arthritis. Cochrane Database Syst Rev 2003, Issue 2. Art. No.: CD003688, doi: 10.1002/14651858.CD003688. 
12. Riemsma RP, Taal E, Kirwan JR, Rasker JJ (2004) Systematic review of rheumatoid arthritis patient education. Arthritis Rheum 51(6):1045-59.

13. Albano MG, Giraudet-Le Quintrec JS, Crozet C, d'Ivernois JF (2010) Characteristics and development of therapeutic patient education in rheumatoid arthritis: Analysis of the 20032008 literature. Joint Bone Spine 77(5):405-10.

14. Arthritis Australia. Women's insights into rheumatoid arthritis. Sydney: Arthritis Australia; 2010.

15. Moher D, Liberati A, Tetzlaff J, Altman DG (2009) Preferred reporting items for systematic reviews and meta-analyses: the PRISMA statement. BMJ 339:b2535.

16. Hyrich KL, Verstappen SMM (2014) Biologic therapies and pregnancy: The story so far. Rheumatology 53(8):1377-85.

17. Giraudet-Le Quintrec J-S, Mayoux-Benhamou A, Ravaud P, Champion K, Dernis E, Zerkak D, Ouslimani A, Courpied J-P, Revel M, Kahan A, Dougados M (2007) Effect of a collective educational program for patients with rheumatoid arthritis: A prospective 12-month randomized controlled trial. J Rheumatol 34(8):1684-91.

18. Mayoux-Benhamou A, Giraudet-Le Quintrec J-S, Ravaud P, Champion K, Dernis E, Zerkak D, Roy C, Kahan A, Revel M, Dougados M (2008) Influence of patient education on exercise compliance in rheumatoid arthritis: A prospective 12-month randomized controlled trial. $\mathrm{J}$ Rheumatol 35(2):216-23.

19. Homer D, Nightingale P, Jobanputra P (2009) Providing patients with information about disease-modifying anti-rheumatic drugs: Individually or in groups? A pilot randomized controlled trial comparing adherence and satisfaction. Musculoskeletal Care 7(2):78-92.

20. Li LC, Adam PM, Backman CL, Lineker S, Jones CA, Lacaille D, Townsend AF, Yacyshyn E, Yousefi C, Tugwell P, Leese J, Stacey D (2014) Proof-of-concept study of a web-based methotrexate decision aid for patients with rheumatoid arthritis. Arthritis Care Res 66(10):1472-81.

21. Bermas BL (2014) Non-steroidal anti inflammatory drugs, glucocorticoids and disease modifying anti-rheumatic drugs for the management of rheumatoid arthritis before and during pregnancy. Curr Opin Rheumatol 26(3):334-40. 
22. Nour K, Laforest S, Gauvin L, Gignac M (2006) Behavior change following a selfmanagement intervention for housebound older adults with arthritis: An experimental study. Int J Behav Nutr Phys Act 3:12.

23. Laforest S, Nour K, Gignac M, Gauvin L, Parisien M, Poirier M (2008) Short-term effects of a self-management intervention on health status of housebound older adults with arthritis. $J$ Appl Gerontol 27(5):539-67.

24. Laforest S, Nour K, Gignac MAM, Gauvin L, Parisien M (2012) The role of social reinforcement in the maintenance of short-term effects after a self-management intervention for frail housebound seniors with arthritis. Can J Aging 31(2):195-207.

25. Pariser D, O'Hanlon A (2005) Effects of telephone intervention on arthritis self-efficacy, depression, pain, and fatigue in older adults with arthritis. J Geriatr Phys Ther 28(3):67-73.

26. Davis GC, White TL (2008) A goal attainment pain management program for older adults with arthritis. Pain Manag Nurs 9(4):171-9.

27. Chui DYY, Lau J, Yau I (2004) An outcome evaluation study of the Rheumatoid Arthritis SelfManagement Programme in Hong Kong. Psychol Health Med 9(3):286-92.

28. Siu AMH, Chui DYY (2004) Evaluation of a community rehabilitation service for people with rheumatoid arthritis. Patient Educ Couns 55(1):62-9.

29. Glazier RH, Badley EM, Lineker SC, Wilkins AL, Bell MJ (2005) Getting a Grip on Arthritis: An educational intervention for the diagnosis and treatment of arthritis in primary care. $\mathrm{J}$ Rheumatol 32(1):137-42.

30. Rapoliene J, Krisciunas A (2006) The effectiveness of occupational therapy in restoring the functional state of hands in rheumatoid arthritis patients. Medicina (Kaunas) 42(10):823-8.

31. Walker D, Adebajo A, Heslop P, Hill J, Firth J, Bishop P, Helliwell PS (2007) Patient education in rheumatoid arthritis: The effectiveness of the ARC booklet and the mind map. Rheumatology 46(10):1593-6.

32. Osborne $\mathrm{RH}$, Wilson $\mathrm{T}$, Lorig $\mathrm{KR}$, McColl GJ (2007) Does self-management lead to sustainable health benefits in people with arthritis? A 2-year transition study of 452 Australians. J Rheumatol 34(5):1112-7. 
33. Mohammad A, Kilcoyne A, Bond U, Regan M, Phelan M (2009) Methotrexate information booklet study 2008. Clin Exp Rheumatol 27(4):649-50.

34. Ellard DR, Barlow JH, Paskins Z, Stapley J, Wild A, Rowe IF (2009) Piloting education days for patients with early rheumatoid arthritis and their partners: A multidisciplinary approach. Musculoskeletal Care 7(1):17-30.

35. Kaariainen $M$, Kukkurainen $M L$, Kyngas $H$, Karppinen $L$ (2011) Improving the quality of rheumatoid arthritis patients' education using written information. Musculoskeletal Care $9(1): 19-24$

36. El Miedany Y, El Gaafary M, El Arousy N, Ahmed I, Youssef S, Palmer D (2012) Arthritis education: The integration of patient-reported outcome measures and patient selfmanagement. Clin Exp Rheumatol 30(6):899-904.

37. Meade T, Dowswell E, Manolios N, Sharpe L (2015) The motherhood choices decision aid for women with rheumatoid arthritis increases knowledge and reduces decisional conflict: A randomized controlled trial. BMC Musculoskelet Disord 16(1):260.

38. Meade T, Sharpe L, Aspanell D, Manolios N. Motherhood choices: A decision aid for women with rheumatoid arthritis. Available from: http://arthritisnsw.org.au/arthritis/research/ra-andmotherhood/; accessed 27 October 2015.

39. Fraenkel L, Peters E, Charpentier P, Olsen B, Errante L, Schoen RT, Reyna V (2012) Decision tool to improve the quality of care in rheumatoid arthritis. Arthritis Care Res 64(7):977-85

40. Ciciriello S, Buchbinder R, Osborne RH, Wicks IP (2014) Improving treatment with methotrexate in rheumatoid arthritis-development of a multimedia patient education program and the MiRAK, a new instrument to evaluate methotrexate-related knowledge. Semin Arthritis Rheum 43(4):437-46.

41. Hammond A, Young A, Kidao R (2004) A randomised controlled trial of occupational therapy for people with early rheumatoid arthritis. Ann Rheum Dis 63(1):23-30.

42. Hammond A, Bryan J, Hardy A (2008) Effects of a modular behavioural arthritis education programme: A pragmatic parallel-group randomized controlled trial. Rheumatology 47(11):1712-8. 
43. Horne R, Hankins M, Jenkins R (2001) The Satisfaction with Information about Medicines Scale (SIMS): A new measurement tool for audit and research. Qual Health Care 10(3):13540.

44. Stacey D, Légaré F, Col Nananda F, Bennett Carol L, Barry Michael J, Eden Karen B, Holmes-Rovner M, Llewellyn-Thomas H, Lyddiatt A, Thomson R, Trevena L, Wu Julie HC. Decision aids for people facing health treatment or screening decisions. Cochrane Database of Systematic Reviews 2014, Issue 1. Art. No.: CD001431. DOI: 10.1002/14651858.CD001431.pub4.

45. Meade T, Sharpe L, Hallab L, Aspanell D, Manolios N (2013) Navigating motherhood choices in the context of rheumatoid arthritis: Women's stories. Musculoskeletal Care 11(2):73-82.

46. Ndosi M, Bremander A, Hamnes B, Horton M, Kukkurainen ML, Machado P, Marques A, Meesters J, Stamm TA, Tennant A, de la Torre-Aboki J, Vliet Vlieland TPM, Zangi HA, Hill J (2013) Validation of the Educational Needs Assessment Tool as a generic instrument for rheumatic diseases in seven European countries. Ann Rheum Dis 73(2122-9.

47. Kavanaugh A, Cush JJ, Ahmed MS, Bermas BL, Chakravarty E, Chambers C, Clowse M, Curtis JR, Dao K, Hankins GD, Koren G, Kim SC, Lapteva L, Mahadevan U, Moore T, Nolan M, Ren Z, Sammaritano LR, Seymour S, Weisman MH (2015) Proceedings from the American College of Rheumatology Reproductive Health Summit: The management of fertility, pregnancy, and lactation in women with autoimmune and systemic inflammatory diseases. Arthritis Care Res 67(3):313-25.

48. Ostensen M (2014) Contraception and pregnancy counselling in rheumatoid arthritis. Curr Opin Rheumatol 26(3):302-7.

49. O'Neill C, Ngian G, Nicholson P, Van Doornum S (2015) Contraceptive use in women with rheumatologic disease taking disease modifying anti-rheumatic drugs. Intern Med J 45(Supplement 2):44.

50. Dalkilic E, Tufan AN, Oksuz MF, Sahbazlar M, Coskun BN, Seniz N, Pehlivan Y, Inanc M (2014) Comparing female-based contraceptive methods in patients with systemic lupus erythematosus, rheumatoid arthritis and a healthy population. Int J Rheum Dis 17(6):653-7. 
Figure 1. Overview of literature screening processes and eligible studies

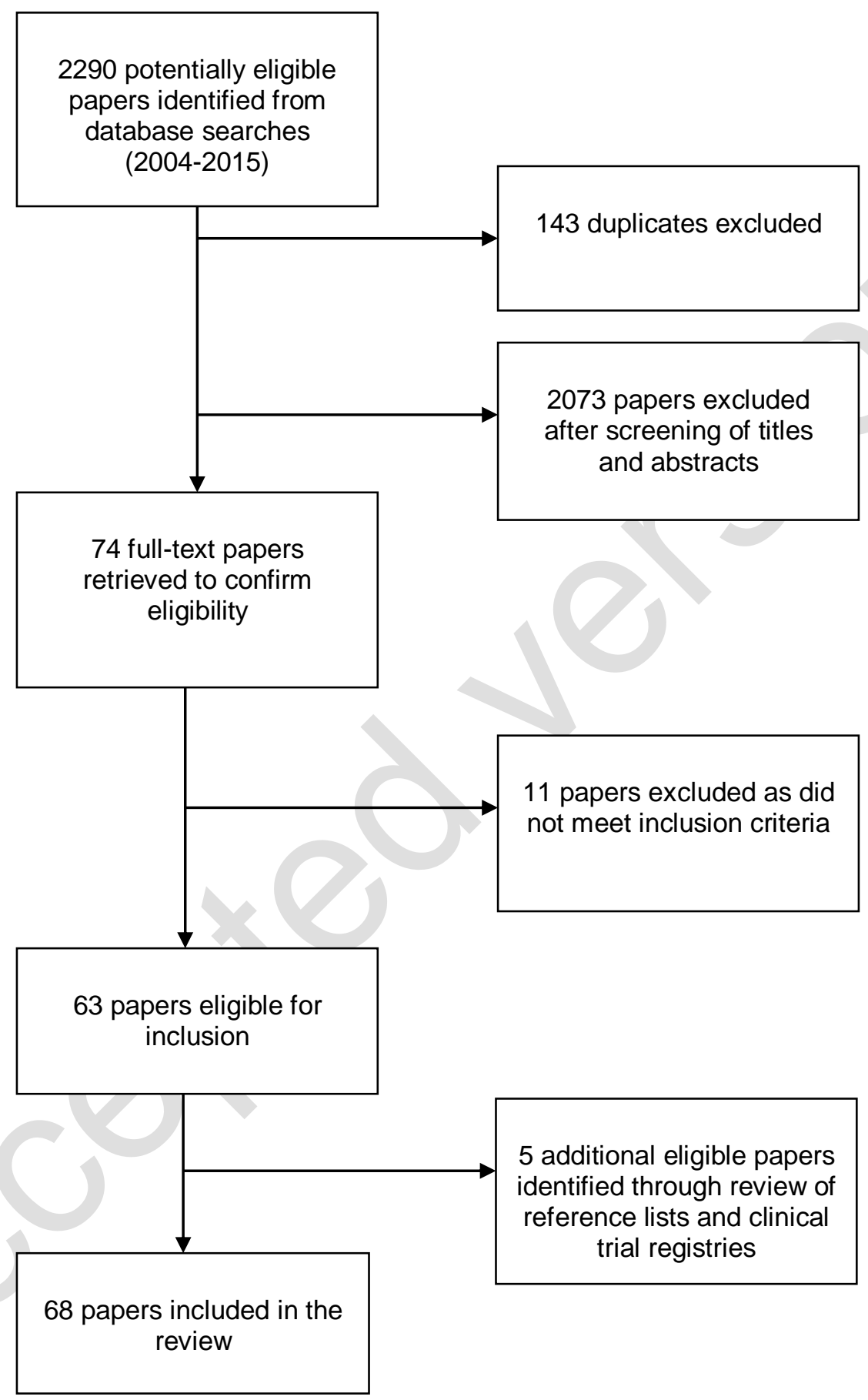


Table 1. Characteristics of included studies

\begin{tabular}{lc}
\hline Characteristic & Studies ( $\mathbf{n = 6 8 )}$ \\
\hline Study design, $n$ (\%) & \\
RCT $^{\star}$ or cluster RCT & $45(66)$ \\
Non-randomised prospective study ${ }^{\dagger}$ & $19(28)$ \\
Pilot RCT & $3(4)$ \\
Mixed-methods study & $1(1)$ \\
Study region, $n$ (\%) & \\
Europe & $30(44)$ \\
North America & $28(41)$ \\
Australia and Asia & $7(10)$ \\
Africa and Middle East & $2(3)$ \\
South America & $1(1)$ \\
Study setting, $n$ (\%) & \\
Hospital or rheumatology clinic / centre / practice & $40(59)$ \\
General community & $14(21)$ \\
Community health or rehabilitation centre & $7(10)$ \\
Other & $6(9)$ \\
Primary care & $1(1)$ \\
Range of sample sizes & \\
Range of mean/median ages & \\
Range of \% of participants with rheumatoid arthritis & \\
Range of \% of female participants & \\
\hline
\end{tabular}

RCT: Randomised controlled trial

* 1 paper reported the results of 2 separate RCTs

${ }^{\dagger}$ Includes cohort, quasi-experimental and pretest-posttest repeated measures designs

\# Data refer to the overall sample for each study (all study participants) 
Table 2. Studies with exclusion criteria related to pregnancy, breastfeeding or age

\begin{tabular}{|c|c|c|c|c|}
\hline First author & Year & Study population & Relevant exclusion criteria & Intervention(s) \\
\hline Davis [26] & 2008 & $\begin{array}{l}\text { People with arthritis } \\
\text { including RA }\end{array}$ & People $<65$ years & $\begin{array}{l}\text { 4-month Goal Attainment Pain } \\
\text { Management Program }\end{array}$ \\
\hline Giraudet-Le Quintrec* [17] & 2007 & People with RA & Pregnancy & 8-week intensive education program \\
\hline Homer [19] & 2009 & People with RA or PsA & $\begin{array}{l}\text { Pregnant women } \\
\text { Nursing mothers }\end{array}$ & $\begin{array}{l}\text { Provision of individual or group } \\
\text { information about DMARDs }\end{array}$ \\
\hline Laforest $^{\dagger}[23]$ & 2008 & People with OA or RA & People $<50$ years & 6-week self-management program \\
\hline Laforest $^{\dagger}[24]$ & 2012 & People with OA or RA & People $<50$ years & $\begin{array}{l}\text { Provision of social reinforcement after } \\
\text { a } 6 \text {-week self-management program }\end{array}$ \\
\hline Li [20] & 2014 & People with RA & $\begin{array}{l}\text { Only included people who } \\
\text { were rheumatologist- } \\
\text { confirmed candidates for } \\
\text { methotrexate }\end{array}$ & $\begin{array}{l}\text { Web-based patient methotrexate } \\
\text { decision aid }\end{array}$ \\
\hline Mayoux-Benhamou* [18] & 2008 & People with RA & Pregnancy & 8-week intensive education program \\
\hline Nour $^{\dagger}[22]$ & 2006 & People with OA or RA & People $<50$ years & 6-week self-management program \\
\hline Pariser [25] & 2005 & People with OA or RA & People $<55$ years & $\begin{array}{l}6 \text {-week telephone-based arthritis self- } \\
\text { management program }\end{array}$ \\
\hline
\end{tabular}

DMARDs: Disease-modifying anti-rheumatic drugs; OA: Osteoarthritis; PsA: Psoriatic arthritis

${ }^{*}$ Related studies (Mayoux-Benhamou et al 2008 reports a post-hoc analysis)

${ }^{\dagger}$ Related studies (Laforest et al 2012 evaluates an additional intervention in the same cohort) 
Table 3. Studies including relevant intervention components and outcome measures

\begin{tabular}{|c|c|c|c|c|}
\hline First author & Year & Study design & $\begin{array}{l}\text { Relevant intervention } \\
\text { component }\end{array}$ & Relevant outcome measure \\
\hline Ciciriello [40] & 2014 & Non-randomised prospective study & $\begin{array}{l}\text { Multimedia patient education } \\
\text { program contained information } \\
\text { about methotrexate use, } \\
\text { conception and breastfeeding }\end{array}$ & MiRAK $^{\dagger}$ \\
\hline Ellard [34] & 2009 & Non-randomised prospective study & $\begin{array}{l}\text { Education day for people with } \\
\text { RA and their partners included a } \\
\text { workshop on relationships }\end{array}$ & No \\
\hline Fraenkel [39] & 2012 & Non-randomised prospective study & $\begin{array}{l}\text { Interactive online educational } \\
\text { module contained a warning } \\
\text { regarding biologics, pregnancy, } \\
\text { pregnancy planning and } \\
\text { breastfeeding }\end{array}$ & No \\
\hline 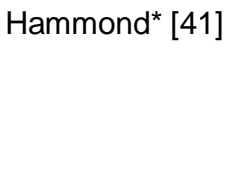 & 2004 & $\mathrm{RCT}$ & $\begin{array}{l}\text { Optional program components } \\
\text { (to meet individual needs) } \\
\text { included discussing the effect of } \\
\text { RA on relationships, and sexual } \\
\text { advice }\end{array}$ & No \\
\hline Hammond $^{*}[42]$ & 2008 & $\mathrm{RCT}$ & $\begin{array}{l}\text { Education modules included } \\
\text { discussion of impact of arthritis } \\
\text { on the family }\end{array}$ & No \\
\hline Homer [19] & 2009 & Pilot RCT & $\begin{array}{l}\text { Discussion about contraception } \\
\text { and fertility }\end{array}$ & SIMS \\
\hline \multirow[t]{2}{*}{ Li [20] } & \multirow[t]{2}{*}{2014} & \multirow[t]{2}{*}{ Mixed-methods study } & $\begin{array}{l}\text { Decision aid information module } \\
\text { addressed planning a family } \\
\text { and methotrexate }\end{array}$ & \multirow[t]{2}{*}{ MiRAK } \\
\hline & & & $\begin{array}{l}\text { Decision aid value clarification } \\
\text { module incorporated rating the } \\
\text { importance of becoming } \\
\text { pregnant / starting a family }\end{array}$ & \\
\hline Meade [37] & 2015 & $\mathrm{RCT}$ & $\begin{array}{l}\text { Forty-five page motherhood } \\
\text { decision aid tool for women with } \\
\text { RA contemplating pregnancy }\end{array}$ & PiRAQ \\
\hline \multirow[t]{2}{*}{$\begin{array}{l}\text { Mohammad } \\
\text { [33] }\end{array}$} & \multirow[t]{2}{*}{2009} & \multirow[t]{2}{*}{ Non-randomised prospective study } & \multirow{2}{*}{$\begin{array}{l}\text { Methotrexate patient information } \\
\text { booklet outlining contraception } \\
\text { use and side effect profile }\end{array}$} & $\begin{array}{l}\text { Awareness of contraception } \\
\text { use }\end{array}$ \\
\hline & & & & $\begin{array}{l}\text { Folic acid use and } \\
\text { awareness of reason for } \\
\text { taking folic acid }\end{array}$ \\
\hline
\end{tabular}

MiRAK: Methotrexate in Rheumatoid Arthritis Knowledge test; PiRAQ: Pregnancy in Rheumatoid Arthritis Questionnaire; SIMS: Satisfaction with Information about Medicines Scale; RCT: Randomised controlled trial; RA: rheumatoid arthritis

${ }^{\dagger}$ Copy of MiRAK instrument obtained from the authors

*Unrelated studies 


\section{Conflict of interest statement}

The authors declare they have no conflicts of interest with respect to this work.

\section{Funding}

This study was supported by unrestricted grant-in-aid funding from AbbVie, Janssen and UCB, with in-kind support from Arthritis and Osteoporosis Victoria. Dr Ackerman is supported by a National Health and Medical Research Council of Australia Public Health (Australian) Early Career Fellowship (\#520004). The study sponsors had no role in the study design, collection, analysis and interpretation of data, in the writing of the manuscript, or in the decision to submit the manuscript for publication. 